\title{
TREINAMENTO E QUALIFICAÇÃO DOS PROFISSIONAIS DE ENFERMAGEM DO BLOCO CIRÚRGICO PARA ATENDIMENTO DE PACIENTES INFECTADOS COM CORONAVIIRUS SARS-CoV-2 EM ÁREAS EXTERNAS
}

https://doi.org/10.5327/Z1414-4425202000040001

$\mathrm{E}$ stamos acostumados a ouvir falar que os profissionais da saúde salvam vidas, mas, atualmente, em meio à pandemia da COVID-19, ouvimos histórias cujos personagens também adoecem e perdem suas vidas. Estimam-se 20 mil mortes destes profissionais em todo o mundo ${ }^{1}$. Segundo o observatório de enfermagem do Conselho Federal de Enfermagem (Cofen), o Brasil é líder mundial no número de profissionais da enfermagem falecidos por COVID-19, totalizando 454 até a primeira semana de novembro ${ }^{2}$.

De acordo com o International Council of Nurses ${ }^{3}$, tais números alertam para as condições e estruturas de atuação inadequadas para estes profissionais, assim como a falta de equipamentos de proteção individual (EPI), além de advertir-nos de que uma segunda onda da pandemia seria ainda mais terrível sem a presença dos profissionais de enfermagem para o cuidado dos pacientes.

No Brasil, um comitê gestor de crise do Cofen ${ }^{4}$ e a Associação Médica Brasileira ${ }^{5}$ estão em constante observação da falta de EPI, para assegurar a segurança dos profissionais de saúde no atendimento aos pacientes contaminados com o coronavírus SARS-CoV-2.

Nesse cenário de incertezas sustentadas, entendemos a necessidade de que os enfermeiros e os técnicos de enfermagem que atuam no bloco cirúrgico (BC) possam ser uma força de trabalho importante para os cuidados dos pacientes críticos na unidade de terapia intensiva (UTI), considerando seu potencial conhecimento em monitorização, hemodinâmica e posicionamento do paciente.

No período de pandemia, a prática cirúrgica foi afetada diretamente pela suspensão dos procedimentos eletivos e pela priorização de cirurgias de urgência e emergência, objetivando a reserva de leitos para pacientes na UTI.

As funções de muitos membros da equipe mudaram como resultado da falta de procedimentos eletivos. Em muitos países, profissionais perioperatórios foram realocados para contribuir e fazer o que fosse necessário, como transferência temporária para unidade diferente, auxiliando colegas no posicionamento do paciente e na colocação e retirada de EPI $^{6}$.

No Brasil, assim como no mundo, a alta demanda de pacientes e cuidados, em instituições públicas ou privadas, exigiu o apoio da enfermagem perioperatória para pacientes com necessidade de cuidados críticos.

Em situações de catástrofe, um plano gerencial de crise deve ser estabelecido. Para a COVID-19, além de estabelecer leitos, equipamentos e recursos materiais, prover profissionais para evitar a sobrecarga do cuidado é uma estratégia desse plano de crise. Segundo a World Health Organization ${ }^{7}$, uma escassez de pessoal, em razão da combinação de ausências de profissionais e do aumento de demanda de serviços, deve ser antecipada e exige um plano para lidar com essa falta, como realocar ou assegurar pessoal adicional.

Como gestor do BC, o primeiro passo era a identificação do quadro de colaboradores que tinham perfil/interesse ou experiências anteriores em unidades críticas. Após, a obrigatoriedade da realização de treinamento, em parceria com a educação continuada, para revisão de procedimentos/rotinas na UTI - visto a demanda da crise, foi possível disponibilizar apenas um dia - e, posteriormente, a inserção destes profissionais na prática, em acompanhamento com outro profissional da área nos primeiros dias, até o momento que a equipe de enfermagem perioperatória tivesse o mesmo olhar para o paciente grave que a equipe de enfermagem intensiva.

Observou-se, em hospitais privados, a migração de técnicos de enfermagem que realizavam curso de graduação em enfermagem e que demonstraram interesse por conta da necessidade de desenvolver habilidades assistenciais de cuidado direto ao paciente; enfermeiros de recuperação anestésica (RA), com maior habilidade para assistência aos pacientes e maior facilidade no desenvolvimento do olhar intensivista; enfermeiros de sala apoiando com domínio no posicionamento cirúrgico. 
O papel mais importante, naquele momento, era preparar os profissionais, caso tivéssemos, para, em contingência, utilizar a sala de RA como uma UTI. E nossa equipe deveria estar preparada para esse desafio.

Como enfermeiras perioperatórias, vivenciamos um misto de sentimentos, aflições sobre a pandemia, medo do desconhecido, possibilidade de se contaminar ou de contaminar algum membro da família ao retornar para casa, necessidade de ajudar como missão de sua profissão, ausência de pacientes em seu setor e incerteza do tempo que tudo isso iria levar. Além disso, adentrar em um novo setor, uma nova rotina, uma nova equipe, novas atribuições e desenvolver outro olhar sobre o paciente grave.

As experiências desse novo olhar aumentaram as competências do enfermeiro perioperatório, de modo a reconhecer a necessidade de intervenções do intraoperatório para melhor cuidado no pós-operatório, como a prevenção de lesões, a acomodação no leito preparado para a necessidade do paciente, a importância do contato familiar, do conforto analgésico, do posicionamento correto, do suporte de drogas vasoativas e suas concentrações, do reconhecimento de instabilidade hemodinâmica e do envolvimento na equipe multidisciplinar como parte do cuidado integral.
As qualidades que tornaram os enfermeiros perioperatórios tão essenciais para os cuidados de saúde, inovação, comunicação, flexibilidade e adaptabilidade foram ampliadas durante a resposta à COVID-196.

Aos poucos, conforme a demanda e a liberação de cirurgias eletivas, a equipe retornou ao BC. A pandemia ainda está vigente e são necessários novos aprendizados e protocolos relacionados à gestão de fluxo de pacientes contaminados com o coronavírus no ambiente cirúrgico. Entretanto, no mês de novembro, após oito meses de pandemia, uma situação de maior controle de necessidade de leitos parece estar estabelecida, e os últimos integrantes da equipe retornam à área perioperatória cheios de histórias, vínculos e competências.

\section{Cristina Silva Sousa (B)}

Pós-doutora em Enfermagem na Saúde do Adulto pela Escola de Enfermagem da Universidade de São Paulo (USP). Enfermeira Sênior do Centro Cirúrgico do Hospital Sírio-Libanês, São Paulo, Brasil. Andrea Alfaya Acuña (1)

Pós-Graduada em Gestão da Atenção à Saúde pela Fundação

Dom Cabral e Instituto Sírio-Libanês de Ensino e Pesquisa. Gerente de Enfermagem do Bloco Operatório do Hospital SírioLibanês, São Paulo, Brasil.

\section{REFERÊNCIAS}

1. International Council of Nurses (INC). El CIE confirma el fallecimiento de 1500 enfermeras por COVID 19 en 44 países y estima que lasmuertes de trabajadores sanitarios por esta enfermedad podrían superar las 20000 en todo el mundo. [Internet]. International Council of Nurses; 2020 [acessado em 30 out. 2020]. Disponível em: www.icn.ch/es/noticias/el-cie-confirma-elfallecimiento-de-1-500-enfermeras-por-covid-19-en-44-paises-y-estima

2. Conselho Federal de Enfermagem (COFEn). Dashboard profissionais infectados com COVID-19 informado pelo serviço de saúde. Observatório da Enfermagem [Internet]. Brasil: Conselho Federal de Enfermagem; 2020 [acessado em 2 nov. 2020]. Disponível em: http://observatoriodaenfermagem.cofen.gov.br

3. International Council of Nurses (INC). ICN calls on WHO member states for health worker COVID-19 data [Internet]. International Council of Nurses; 2020 [acessado em 25 out. 2020]. Disponível em: www.2020yearofthenurse.org/ story/icn-calls-on-who-member-states-for-health-worker-covid-19-data
4. Santos VC, Persegona MFM, Souza EF, Almeida WC, Filete M, Silva MCN. Comitê Gestor de Crise do Coronavirus no âmbito do COFEn. Enferm Foco. 2020;11(2):6-10. https://doi.org/10.21675/2357707X.2020.v11.n2.4213

5. Associação Médica Brasileira (AMB). Faltam EPIs em todo o país. [Internet]. Associação Médica Brasileira; 2020 [acessado em 10 out. 2020]. Disponível em: https://amb.org.br/epi

6. Retzlaff KJ. Staffing and orientation during the COVID-19 Pandemic. AORN J. 2020;112(3):206-11. http://doi.org/10.1002/ aorn. 13148

7. World Health Organization (WHO). Hospital preparedness for epidemics. [Internet] Suiça: World Health Organization; 2014. 76 p [acessado em 2 nov. 2020]. Avail Disponível em: https://www.who. int/publications-detail/hospital-preparedness-for-epidemics 